\title{
To Study the Effect of Input Parameters on Surface Roughness of Cylindrical Grinding of Heat Treated AISI 4140 Steel
}

\author{
Karanvir Singh, Parlad Kumar, Khushdeep Goyal* \\ Department of Mechanical Engineering, Punjabi University, Patiala-147002, India \\ *Corresponding author: khushgoyal@yahoo.com
}

Received March 24, 2014; Revised March 29, 2014; Accepted May 25, 2014

\begin{abstract}
In this present work, The effect of input parameters viz. grinding wheel speed, work-piece speed, abrasive grain size, depth of cut, concentration of cutting fluid, and number of passes has been found on the surface roughness of cylindrical grinded AISI 4140 steel has been found. The other parameters like feed rate, diameter of work-piece, coolant flow rate, etc. are kept constant. Three levels of each variable have been selected except wheel speed. Two levels of wheel speed have been taken. Heat treated AISI 4140 steel is selected as the work-piece material. The experiment is designed by using Taguchi's L18 orthogonal array. The effect of all the input parameters on the output responses have been analyzed using analysis of variance (ANOVA). The result reveals that depth of cut and work-piece speed are the most significant to influence surface roughness, followed by work speed. The optimum set of input parameters for minimizing the surface roughness has also been found.
\end{abstract}

Keywords: input parameters, cylindrical grinding, surface roughness, number of passes

Cite This Article: Karanvir Singh, Parlad Kumar, and Khushdeep Goyal, "To Study the Effect of Input Parameters on Surface Roughness of Cylindrical Grinding of Heat Treated AISI 4140 Steel.” American Journal of Mechanical Engineering, vol. 2, no. 3 (2014): 58-64. doi: 10.12691/ajme-2-3-2.

\section{Introduction}

Grinding is one of the most popular machining processes to improve surface quality and to obtain dimensional accuracy of a work piece. It is used as the finishing process as well as the main machining process. Grinding is usually the last finishing operation to be completed on the work piece and hence any deviations in quality such as geometrical errors and surface finish cannot be passed on to the next operation. In cylindrical grinding surface roughness is one of the important response factors. Surface roughness gives the quality of machined surface which is important to reduce the frictional force while out-of-roundness is of great importance in case of shafts, axles, pistons, piston pins, crankshafts, roller bearings as out of roundness in these components can lead to excessive noise, vibrations, component failure, etc. so there is need to optimize the input parameters to have minimum out of roundness error. In the present study experiments are conducted to find optimum value of input parameters for minimum surface roughness. The selected input parameters are grinding wheel speed, work-piece speed, abrasive grain size, depth of cut, concentration of cutting fluid, and number of passes while surface roughness and out-of-roundness are desired responses. The other parameters like feed rate, diameter of work-piece, coolant flow rate, etc. are kept constant. Heat treated AISI 4140 steel is selected as the work-piece material. The experiment is designed by using Taguchi's L18 orthogonal array. The effect of all the input parameters on the output responses have been analyzed using analysis of variance (ANOVA). The effect of variation in input parameters has been studied on the output responses. Plots of $\mathrm{S} / \mathrm{N}$ ratio have been used to determine the best relationship between the responses and the input parameters, in other words, optimum set of input parameters for minimum surface roughness and minimum out-of-roundness are determined.

\section{Literature Survey}

Shih et al. [1] used vitreous bond CBN wheel for high speed grinding of zirconia and M2 tool steel. The authors conducted experiments on Weldon AGN5 CNC cylindrical grinding machine. The authors concluded that both normal and tangential grinding forces were reduced with high speed grinding, however it does not improve surface finish and roundness of ground parts. The authors further concluded that, decreasing the speed of wheel during truing and increasing it during grinding helps to reduce the grinding forces mainly for M2 steel. For coolant flow rate, the high flow rate (62.5 litre/ min) help to eliminate layer of zirconia powder from wheel while grinding zirconia and burning marks on ground M2 parts. Nathan et al. [2] carried out an in-process monitoring of grinding burn in cylindrical grinding of steel. The authors found that the spark temperature was a good 
representative of the grinding zone temperature and can be used for process monitoring purposes. In case of C60 steel the grinding burn occurred when the spark temperature exceeded $900^{\circ} \mathrm{C}$. The authors further concluded that the 'time to burn' was a useful wheel life parameter which is the time after which the burn occurred from start of grinding with dressed wheel during continuous grinding. Shaji et al. [3] conducted the experiments to analyze the process parameters in surface grinding with graphite as lubricant based on taguchi method. The fine graphite powder, mixed with water soluble oil and little quantity of grease to a paste form was used as lubricant. EN 31 steel bulk hardened to HRC of 60 was used as a work piece. Work speed, feed, in feed and mode of dressing were used as input parameters. The authors concluded that in case of graphite as lubricant, the tangential force and surface roughness were lower and normal force was higher as compared to those in traditional grinding. Sahin [4] investigated the effect of optimal testing parameters on the wear behavior of AISI 1340, AISI 1020 and AISI 5150 steel. The author conducted the experiments on a pin-ondisc apparatus. Three variables were selected as input parameters viz. abrasive grain size, applied load and sliding distance. The wear of the work piece was selected as response factor. The experiments were conducted to analyze the influence of input parameters on weight loss of various steel work pieces. The author concluded that for AISI 1340 steel the main parameter affecting the wear was abrasive grain size, followed by the sliding distance. The applied load had a much lower effect. For AISI 1020 and AISI 5150 steels, the dominating parameter was sliding distance as compared to applied load and abrasive grain size. Kumar et al. [5] aimed at finding the optimal material removal and effect of process parameters of cylindrical grinding machine by Taguchi method. Depth of cut and cutting speed were selected as input parameters and material removal rate (MRR) was selected as response parameter. The experiment was designed using L-9 orthogonal array with three levels of each input variables. Analysis of variance (ANOVA) was used to investigate the effect of parameters which revealed that the influence of the cutting speed was significantly more than depth of cut. The authors found that the optimum MRR was 19.906 $\mathrm{mm}^{3} / \mathrm{s}$ with cutting speed of $41.07 \mathrm{~m} / \mathrm{min}$ and depth of cut $0.020 \mathrm{~mm}$.

Agarwal et al. [6] worked on modeling and prediction of surface roughness in ceramic grinding. The authors developed an analytical model based on analysis of undeformed chip thickness and the grooves left by the grinding wheel grains on the surface of ceramic work piece for the prediction of surface roughness of ground ceramics. The model also incorporated the overlapping effect of grooves left by grains which made the model more realistic. The model was compared with the existing models and it was concluded that surface roughness was increased with the increase in feed and depth of cut. Further, the increase in depth of cut increased the maximum chip thickness which resulted in poor surface quality. Pal et al. [7] worked on optimization of grinding parameters for minimum surface roughness by Taguchi parametric optimization technique. The authors conducted the experiments on a universal tool and cutter grinding machine with different grain sized aluminum oxide white grinding wheels, on different materials EN 24, EN 31 and
Die steel. The work speed, material hardness and type of grinding wheel were selected as input variables. The surface roughness was selected as output parameter. An L9 orthogonal array was used to design the experiments. The authors found that there was decrease in surface roughness with the increase in material hardness. When the speed of work piece was changed it was found that the surface roughness decreases when speed was changed from 100 to $160 \mathrm{rpm}$ and again decreases when speed further increased to $200 \mathrm{rpm}$. The authors also concluded that when grinding wheel grain size change from G46 to G60, the surface roughness decreases, but at grain size G80 roughness increases considerably. George et al. [8] studied the surface roughness and its prediction in cylindrical grinding process based on taguchi method of optimization. The material hardness, work piece speed, and depth of cut were selected as input parameters and surface roughness was selected as response factor. An L9 orthogonal array was used for designing the experiment. The experiments were conducted on En 24, EN 31, and EN 353 materials using a cylindrical grinding machine. Surface roughness was measured using Mitotoyo surf test SJ-400 roughness tester. The authors found that the surface roughness decreases as the material hardness was increased. When the work piece speed was increased from 60 to $120 \mathrm{rpm}$ the surface roughness decreased. The surface roughness was also decreased when the depth of cut was increased from 10 to $20 \mu \mathrm{m}$. The minimum surface roughness obtained was $0.47 \mu \mathrm{m}$ at hardness value of $64 \mathrm{HRC}$, at work piece speed of $120 \mathrm{rpm}$ and when depth of cut was $20 \mu \mathrm{m}$. Regression equation was formulated based on obtained results.

\section{Objectives of Present Investigation}

On the basis of the literature following objective have been decided for this study:

1. To work out optimum set of input parameters for minimum surface roughness by using ANOVA method.

2. To confirm the validity of optimum set of input parameters obtained by conducting confirmation experiments.

\section{Experimentation}

In this study AISI 4140 steel is selected as the work piece material, which is a chromium-molybdenum high tensile strength steel. It offers a very good balance of strength, toughness and wears resistance. AISI 4140 steel is used in manufacturing of axles, conveyor parts, gears, spindles, shafts, studs, pinions, pump shafts, rams, ring gears etc. Figure 1 shows the pictorial view of specimen used for this experimentation.

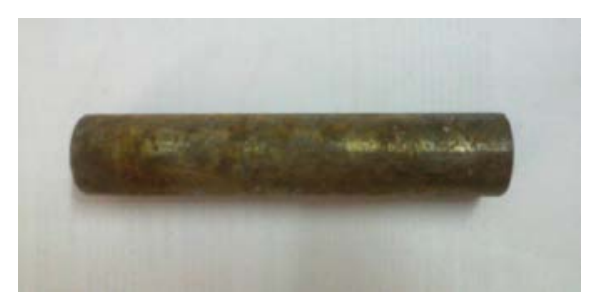

Figure 1. Specimen cut from raw material 
Two factors i.e. surface roughness and out-of-roundness have been selected as response factors. The various parameters that influence these response factors are material of work piece, diameter of work piece, grain size of abrasive particles, grinding wheel speed, work piece speed, axial feed rate, depth of cut, coolant flow rate, concentration of cutting fluid, number of passes, etc. It has been found from the review of literature that the parameters like grinding wheel speed, work piece speed, grain size of abrasive particles, depth of cut, concentration of cutting fluid and number of passes are most critical and these have been selected as input parameters, in this study. For experimentation, two or three levels have been selected for each selected input parameter. The list of various input parameters along with their levels is given in Table 1. The L18 orthogonal array along with independent variables and their selected levels used for the experiment is shown in Table 2. The cylindrical grinding is performed on HMT G9 cylindrical grinding machine.

Table 1. Different input parameters and their levels

\begin{tabular}{|c|c|c|c|}
\hline \multirow{2}{*}{ Input Parameters } & \multicolumn{3}{|c|}{ Levels } \\
\cline { 2 - 4 } & Level-1 & Level-2 & Level-3 \\
\hline Grinding wheel speed (rpm) & 2100 & 2640 & - \\
\hline Work piece speed (rpm) & 250 & 500 & 710 \\
\hline Grain size (mesh/inch) & 60 & 46 & 36 \\
\hline Depth of cut ( $\mu \mathrm{m})$ & 15 & 20 & 25 \\
\hline $\begin{array}{c}\text { Concentration of cutting fluid } \\
\text { (in \%) }\end{array}$ & 3 & 4 & 5 \\
\hline
\end{tabular}

Table 2. L18 experimental design for selected input parameters and their levels

\begin{tabular}{|c|c|c|c|c|c|c|}
\hline $\begin{array}{c}\text { Exp. } \\
\text { No. }\end{array}$ & $\begin{array}{c}\text { Wheel } \\
\text { speed } \\
(\mathrm{rpm})\end{array}$ & $\begin{array}{c}\text { Work } \\
\text { speed } \\
(\mathrm{rpm})\end{array}$ & $\begin{array}{c}\text { Grain size } \\
\text { (mesh/inch) }\end{array}$ & $\begin{array}{c}\text { Depth } \\
\text { of cut } \\
(\mu \mathrm{m})\end{array}$ & $\begin{array}{c}\text { Concentration of } \\
\text { cutting fluid } \\
\text { (in\%) }\end{array}$ & $\begin{array}{c}\text { Number } \\
\text { of passes }\end{array}$ \\
\hline 1 & 2100 & 250 & 60 & 15 & 3 & 2 \\
\hline 2 & 2100 & 250 & 46 & 20 & 4 & 3 \\
\hline 3 & 2100 & 250 & 36 & 25 & 5 & 4 \\
\hline 4 & 2100 & 500 & 60 & 15 & 4 & 3 \\
\hline 5 & 2100 & 500 & 46 & 20 & 5 & 4 \\
\hline 6 & 2100 & 500 & 36 & 25 & 3 & 2 \\
\hline 7 & 2100 & 710 & 60 & 20 & 3 & 4 \\
\hline 8 & 2100 & 710 & 46 & 25 & 4 & 2 \\
\hline 9 & 2100 & 710 & 36 & 15 & 5 & 3 \\
\hline 10 & 2640 & 250 & 60 & 25 & 5 & 3 \\
\hline 11 & 2640 & 250 & 46 & 15 & 3 & 4 \\
\hline 12 & 2640 & 250 & 36 & 20 & 4 & 2 \\
\hline 13 & 2640 & 500 & 60 & 20 & 5 & 2 \\
\hline 14 & 2640 & 500 & 46 & 25 & 3 & 3 \\
\hline 15 & 2640 & 500 & 36 & 15 & 4 & 4 \\
\hline 16 & 2640 & 710 & 60 & 25 & 4 & 4 \\
\hline 17 & 2640 & 710 & 46 & 15 & 5 & 2 \\
\hline 18 & 2640 & 710 & 36 & 20 & 3 & 3 \\
\hline
\end{tabular}

\section{Results and Discussion}

\subsection{Results for Surface Roughness}

The results for all the experiments conducted according to Taguchi's orthogonal array are given in this section. The results observed for surface roughness are shown in Table 3.

Table 3. Results for surface roughness $\left(R_{a}\right)$

\begin{tabular}{|c|c|c|c|c|c|c|c|}
\hline \multirow{2}{*}{$\begin{array}{l}\text { Exp. } \\
\text { No. }\end{array}$} & A & B & C & D & E & F & \multirow{2}{*}{$\begin{array}{c}\text { Surface Roughness } \\
\qquad(\mu \mathrm{m})\end{array}$} \\
\hline & $\begin{array}{c}\text { Wheel speed } \\
\text { (rpm) }\end{array}$ & $\begin{array}{c}\text { Work speed } \\
(\mathrm{rpm})\end{array}$ & $\begin{array}{c}\text { Grain size } \\
\text { (mesh/inch) }\end{array}$ & $\begin{array}{c}\text { Depth of cut } \\
(\mu \mathrm{m})\end{array}$ & $\begin{array}{c}\text { Concentration of cutting } \\
\text { fluid (in \%) } \\
\end{array}$ & $\begin{array}{c}\text { Number of } \\
\text { passes }\end{array}$ & \\
\hline 1 & 2100 & 250 & 60 & 15 & 3 & 2 & 0.42 \\
\hline 2 & 2100 & 250 & 46 & 20 & 4 & 3 & 0.55 \\
\hline 3 & 2100 & 250 & 36 & 25 & 5 & 4 & 0.45 \\
\hline 4 & 2100 & 500 & 60 & 15 & 4 & 3 & 0.39 \\
\hline 5 & 2100 & 500 & 46 & 20 & 5 & 4 & 0.48 \\
\hline 6 & 2100 & 500 & 36 & 25 & 3 & 2 & 0.58 \\
\hline 7 & 2100 & 710 & 60 & 20 & 3 & 4 & 0.50 \\
\hline 8 & 2100 & 710 & 46 & 25 & 4 & 2 & 0.49 \\
\hline 9 & 2100 & 710 & 36 & 15 & 5 & 3 & 0.47 \\
\hline 10 & 2640 & 250 & 60 & 25 & 5 & 3 & 0.56 \\
\hline 11 & 2640 & 250 & 46 & 15 & 3 & 4 & 0.51 \\
\hline 12 & 2640 & 250 & 36 & 20 & 4 & 2 & 0.61 \\
\hline 13 & 2640 & 500 & 60 & 20 & 5 & 2 & 0.49 \\
\hline 14 & 2640 & 500 & 46 & 25 & 3 & 3 & 0.39 \\
\hline 15 & 2640 & 500 & 36 & 15 & 4 & 4 & 0.52 \\
\hline 16 & 2640 & 710 & 60 & 25 & 4 & 4 & 0.47 \\
\hline 17 & 2640 & 710 & 46 & 15 & 5 & 2 & 0.34 \\
\hline 18 & 2640 & 710 & 36 & 20 & 3 & 3 & 0.42 \\
\hline
\end{tabular}

It is observed that the minimum surface roughness obtained is $0.34 \mu \mathrm{m}$ which is obtained at grinding wheel size 46 , depth of cut $15 \mu \mathrm{m}$, concentration of cutting fluid 
$5 \%$ and number of passes 2 . While the maximum surface roughness obtained is $0.56 \mu \mathrm{m}$ at grinding wheel speed of 2640 rpm, work piece speed of $250 \mathrm{rpm}$, grain size 60, depth of cut $25 \mu \mathrm{m}$, concentration of cutting fluid $5 \%$ and number of passes 3 .

Table 4. S/N ratio for surface roughness $\left(\mathrm{R}_{\mathrm{a}}\right)$

\begin{tabular}{|c|c|c|c|c|c|c|c|c|}
\hline \multirow{2}{*}{$\begin{array}{l}\text { Exp. } \\
\text { No. }\end{array}$} & A & B & C & $\mathrm{D}$ & $\mathrm{E}$ & $\mathrm{F}$ & \multirow{2}{*}{$\begin{array}{c}\text { Surface } \\
\text { Roughness }(\mu \mathrm{m})\end{array}$} & \multirow{2}{*}{$\begin{array}{r}\mathrm{S} / \mathrm{N} \\
\text { ratio }\end{array}$} \\
\hline & $\begin{array}{l}\text { Wheel speed } \\
\text { (rpm) }\end{array}$ & $\begin{array}{l}\text { Work speed } \\
\text { (rpm) }\end{array}$ & $\begin{array}{l}\text { Grain size } \\
\text { (mesh/inch) }\end{array}$ & $\begin{array}{l}\text { Depth of cut } \\
(\mu \mathrm{m})\end{array}$ & $\begin{array}{c}\text { Concentration of cutting } \\
\text { fluid (in \%) }\end{array}$ & $\begin{array}{c}\text { Number of } \\
\text { passes }\end{array}$ & & \\
\hline 1 & 2100 & 250 & 60 & 15 & 3 & 2 & 0.42 & 7.535 \\
\hline 2 & 2100 & 250 & 46 & 20 & 4 & 3 & 0.55 & 5.193 \\
\hline 3 & 2100 & 250 & 36 & 25 & 5 & 4 & 0.45 & 6.936 \\
\hline 4 & 2100 & 500 & 60 & 15 & 4 & 3 & 0.39 & 8.179 \\
\hline 5 & 2100 & 500 & 46 & 20 & 5 & 4 & 0.48 & 6.375 \\
\hline 6 & 2100 & 500 & 36 & 25 & 3 & 2 & 0.58 & 4.731 \\
\hline 7 & 2100 & 710 & 60 & 20 & 3 & 4 & 0.50 & 6.020 \\
\hline 8 & 2100 & 710 & 46 & 25 & 4 & 2 & 0.49 & 6.196 \\
\hline 9 & 2100 & 710 & 36 & 15 & 5 & 3 & 0.47 & 6.558 \\
\hline 10 & 2640 & 250 & 60 & 25 & 5 & 3 & 0.56 & 5.036 \\
\hline 11 & 2640 & 250 & 46 & 15 & 3 & 4 & 0.51 & 5.848 \\
\hline 12 & 2640 & 250 & 36 & 20 & 4 & 2 & 0.61 & 4.293 \\
\hline 13 & 2640 & 500 & 60 & 20 & 5 & 2 & 0.49 & 6.196 \\
\hline 14 & 2640 & 500 & 46 & 25 & 3 & 3 & 0.39 & 8.179 \\
\hline 15 & 2640 & 500 & 36 & 15 & 4 & 4 & 0.52 & 5.680 \\
\hline 16 & 2640 & 710 & 60 & 25 & 4 & 4 & 0.47 & 6.558 \\
\hline 17 & 2640 & 710 & 46 & 15 & 5 & 2 & 0.34 & 9.370 \\
\hline 18 & 2640 & 710 & 36 & 20 & 3 & 3 & 0.42 & 7.535 \\
\hline
\end{tabular}

\subsection{S/N Ratios for Surface Roughness}

The signal to noise ratio $\mathrm{S} / \mathrm{N}$ ratio gives the idea about the variations present in the process. The $\mathrm{S} / \mathrm{N}$ ratios have been calculated to determine the major contributing parameters for varying out-of-roundness values as shown in Table 4.

In this experimental work, surface roughness is based on principle of 'lower is better' which is logarithmic function based on mean square deviation (MSD), given by

$$
S / N_{L B}=-10 \log (M S D)=-10 \log \left[\frac{1}{r} \sum_{i=0}^{r} y_{i}^{2}\right]
$$

MSD $=$ Mean square deviation

$\mathrm{y}_{\mathrm{i}}=$ Observed value of the response characteristic $\mathrm{r}=$ Number of repetitions

\subsection{Anova for Surface Roughness $\left(\mathbf{R}_{\mathrm{a}}\right)$}

Results obtained from the experiments were analyzed using analysis of variance or ANOVA method. ANOVA method was applied to signal to noise ratio. For ANOVA analysis sum of squares $\left(\mathrm{SS}_{\mathrm{A}}\right)$, sum of squares total $\left(\mathrm{SS}_{\mathrm{T}}\right)$, sum of squares error $\left(\mathrm{SS}_{\mathrm{E}}\right)$ degree of freedom (DOF), variance and F-ratio have been calculated using following equations:

i. Calculating sum of squares total $\left(\mathrm{SS}_{\mathrm{T}}\right)$ :

$$
S S_{T}=\sum_{i=1}^{n}\left(y_{i}-\bar{T}\right)^{2}
$$

Where

$\mathrm{n}=$ number of response observations

$\bar{T}=$ mean of all observations

$\mathrm{y}_{\mathrm{i}}=$ ith observation

ii. Calculating sum of squares (SS):

$$
S S_{A}=\left[\sum_{i=1}^{K_{A}}\left(\frac{A_{i}^{2}}{n_{A i}}\right)\right]-\frac{T^{2}}{N}
$$

Where

$\mathrm{SS}_{\mathrm{A}}=$ Square deviation of factor $\mathrm{A}$

$A_{i}=$ Average of all observations under $A_{i}$ level

$\mathrm{T}=$ Sum of all observations

iii. Calculating sum of squares error $\left(\mathrm{SS}_{\mathrm{E}}\right)$ :

$$
S S_{E}=\sum_{j=1}^{K_{A}} \sum_{i=1}^{n_{A i}}\left(y_{i}-\bar{A}_{j}\right)
$$

Where

$\mathrm{y}_{\mathrm{i}}=i$ th observation

$\mathrm{n}_{\mathrm{Ai}}=$ Number of observations under $\mathrm{A}_{\mathrm{i}}$ level

iv. Calculating variance, $\mathrm{F}$ - ratio and percentage contribution

Variance is the ratio between sum of squares and degree of freedom.

$$
\text { Variance }=\frac{S S_{A}}{D O F}
$$

While F- ratio is the ratio between variance of each parameter and variance of residual error. Percentage contribution is the percentage of contribution of input parameter in the response factor which is the ratio of square deviation of factor $\mathrm{A}$ and sum of squares total i.e.

$$
\text { Pcontribution }=\frac{S S_{A}}{S S_{T}} \times 100
$$

After calculating for $\mathrm{S} / \mathrm{N}$ ratios for all the experiments ANOVA is carried out for obtained $\mathrm{S} / \mathrm{N}$ ratios as shown in Table 5. The purpose of analysis of variance is to investigate the parameters that significantly affect the quality characteristics. Further, the percentage 
contribution of various input parameters is also calculated and shown in Table 5.

Table 5. Analysis of variance for $\mathrm{S} / \mathrm{N}$ ratios of surface roughness $\left(R_{a}\right)$

\begin{tabular}{|c|c|c|c|c|c|c|}
\hline Source of variation & Sum of squares & Degree of freedom & Variance & F-ratio & Status & Percentage contribution \\
\hline Wheel speed & 0.053 & 1 & 0.053 & 0.14 & Insignificant & $0.303 \%$ \\
\hline Work-piece speed & 4.626 & 2 & 2.313 & 6.08 & Significant & $26.50 \%$ \\
\hline Grain size & 2.59 & 2 & 1.295 & 3.40 & Insignificant & $14.83 \%$ \\
\hline Depth of cut & 5.10 & 2 & 2.55 & 6.71 & Significant & $29.21 \%$ \\
\hline Concentration of Cutting fluid & 1.86 & 2 & 0.93 & 2.44 & Insignificant & $10.65 \%$ \\
\hline No. of passes & 0.95 & 2 & 0.47 & 1.25 & Insignificant & $5.44 \%$ \\
\hline Residual error & 2.28 & 6 & 0.38 & & & $13.06 \%$ \\
\hline Total & 17.46 & 17 & & & & $100 \%$ \\
\hline
\end{tabular}

Since $\mathrm{F}_{0.05}=5.99$ and $\mathrm{F}_{0.05}=5.14$, the depth of cut and work piece speed are significant parameters for surface roughness. The error variation of $13.06 \%$ is due to uncontrollable parameters and/or some parameters that would not have been included that may affect the surface roughness. The wheel speed, grain size, concentration of cutting fluid and number of passes are insignificant parameters. From percentage contribution it is found that influence of the depth of cut is significantly larger than the other parameters followed by work piece speed, grain size, concentration of cutting fluid, number of passes, and grinding wheel speed has lowest percentage contribution. Response values for $\mathrm{S} / \mathrm{N}$ ratios for surface roughness are given in Table 6 .

Table 6. Response table for mean $\mathrm{S} / \mathrm{N}$ ratios of surface roughness $\left(\mathrm{R}_{\mathbf{a}}\right)$

\begin{tabular}{|c|c|c|c|c|c|c|}
\hline \multirow{2}{*}{ Level } & A & B & C & D & E & F \\
\cline { 2 - 7 } & Wheel speed & Work-piece speed & Grain size & Depth of cut & Concentration of cutting fluid & Number of passes \\
\hline 1. & 6.414 & 5.807 & 6.587 & $7.195^{*}$ & 6.641 & 6.387 \\
\hline 2. & $6.522^{*}$ & 6.557 & $6.860^{*}$ & 5.935 & 6.016 & $6.780^{*}$ \\
\hline 3. & - & $7.039 *$ & 5.955 & 6.272 & $6.745^{*}$ & 6.236 \\
\hline Delta & 0.108 & 1.232 & 0.905 & 1.26 & 0.729 & 0.544 \\
\hline Rank & 6 & 2 & 3 & 1 & 4 & 5 \\
\hline
\end{tabular}

\subsection{Main Effect Plots for Surface Roughness}

The effect of grinding wheel speed on mean $\mathrm{S} / \mathrm{N}$ ratios of surface roughness is shown in Figure 2. The $\mathrm{S} / \mathrm{N}$ ratio increases slightly when grinding wheel speed is increased from $2100 \mathrm{rpm}$ to $2640 \mathrm{rpm}$. It is found that the surface roughness decreases as we increase grinding wheel speed. It may be due to the fact that as grinding wheel speed is increased more number of grits engages to remove material from particular area on the surface of work piece resulting into good surface finish.

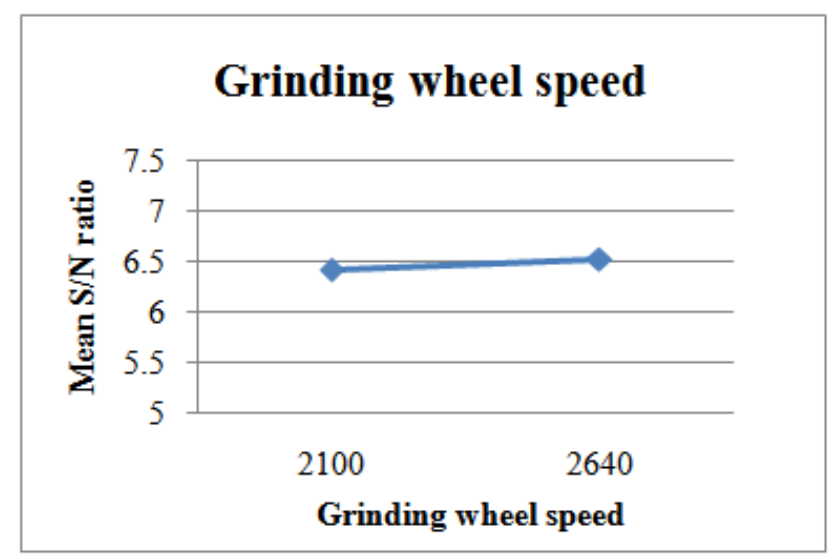

Figure 2. Main effect plot for means of S/N ratios of SR for grinding wheel speed

For increase in work piece speed the mean $\mathrm{S} / \mathrm{N}$ ratio increases and surface roughness decreases. The $\mathrm{S} / \mathrm{N}$ ratio increases as work piece speed is increased from $250 \mathrm{rpm}$ to $500 \mathrm{rpm}$ and from $500 \mathrm{rpm}$ to $710 \mathrm{rpm}$. In this case $\mathrm{S} / \mathrm{N}$ ratio is maximum for work piece speed of $710 \mathrm{rpm}$ as shown in Figure 3. Ptashnikov [9] also found that increase in the work piece speed in a wide range leads to better surface roughness with small depth of cut. Similarly

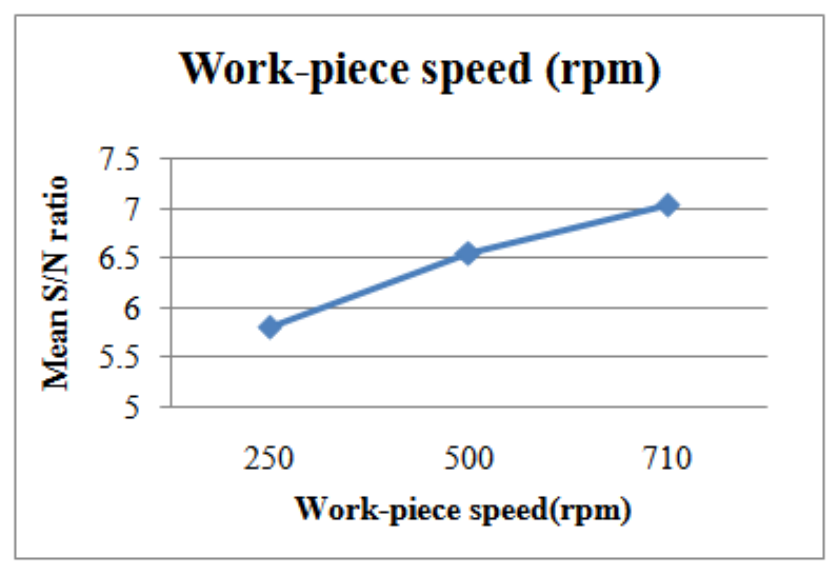

Figure 3. Main effect plot for means of S/N ratios of SR for work piece speed

The effect of grain size on $\mathrm{S} / \mathrm{N}$ ratio is shown in Figure 4. The $\mathrm{S} / \mathrm{N}$ ratio increases slightly when grain size is increased from $60 \mathrm{mesh} /$ inch to 46 mesh/inch and then decreases as grain size is further increased to 36 mesh/ inch and $\mathrm{S} / \mathrm{N}$ ratio is higher at grain size of 46 mesh/inch which corresponds to minimum surface roughness and is optimum level for grain size. 


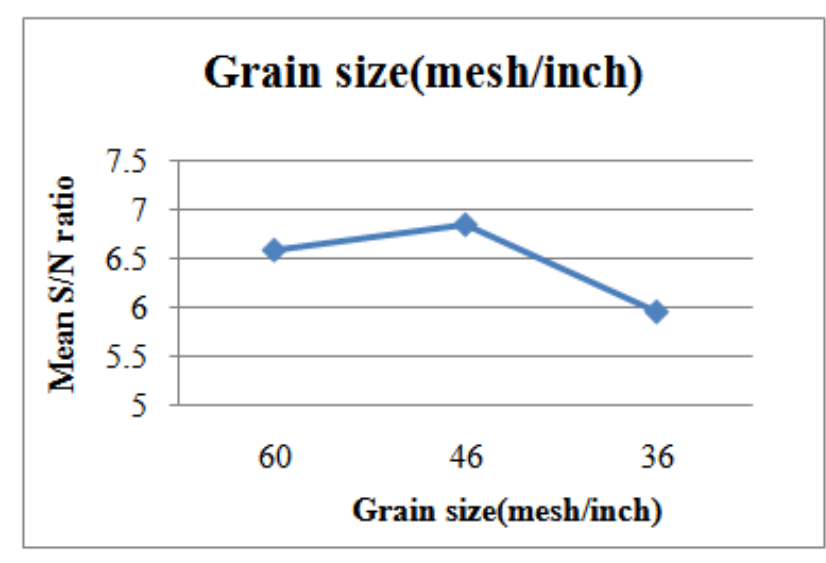

Figure 4. Main effect plot for means of $\mathrm{S} / \mathrm{N}$ ratios of $\mathrm{SR}$ for grain size

In case of depth of cut the $\mathrm{S} / \mathrm{N}$ ratio decreases when depth of cut was increased from $15 \mu \mathrm{m}$ to $20 \mu \mathrm{m}$ and then increases as depth of cut was further increased to $25 \mu \mathrm{m}$, in other words we can say that surface roughness first decreases and then decreases as shown in Figure 5. The $\mathrm{S} / \mathrm{N}$ ratio is higher at depth of cut of $15 \mu \mathrm{m}$ which means it is optimum level of depth of cut. Plastic deformation is desirable for low surface roughness and it dominates only when depth of cut was low [10] and optimum level of depth of cut obtained in this work is also low i.e. $15 \mu \mathrm{m}$.

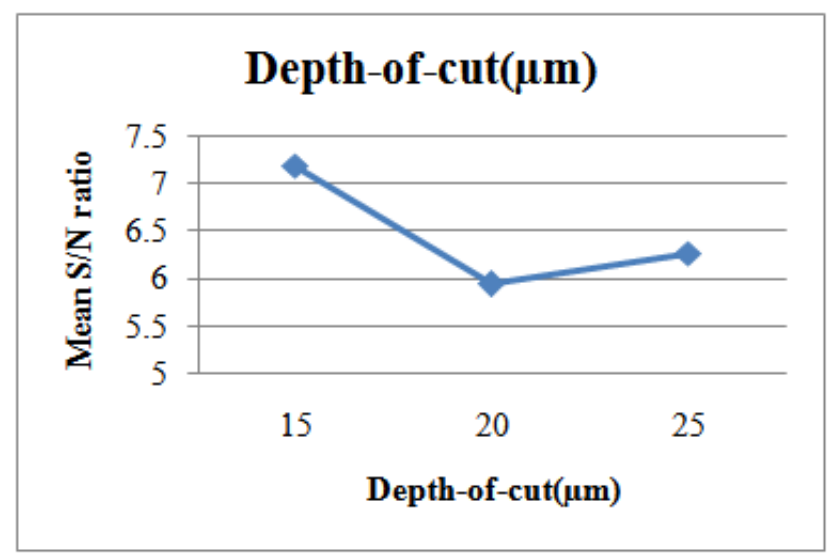

Figure 5. Main effect plot for means of S/N ratios of SR for depth of cut

The $\mathrm{S} / \mathrm{N}$ ratio first decreases and then increases as concentration of cutting fluid is increased from $3 \%$ to $4 \%$ and further to $5 \%$. The higher mean $\mathrm{S} / \mathrm{N}$ ratio corresponds to $5 \%$ concentration of cutting fluid which sows is gives low surface finish as shown in Figure 6.

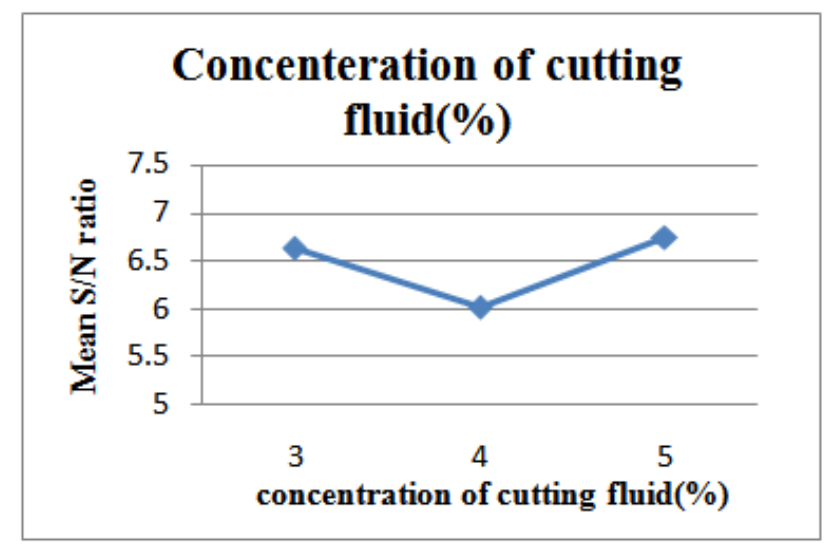

Figure 6. Main effect plot for means of $\mathrm{S} / \mathrm{N}$ ratios of $\mathrm{SR}$ for concenteration of cutting fluid
The effect of number of passes is shown in Figure 7. The $\mathrm{S} / \mathrm{N}$ ratio increases as number of passes is increased from 2 to 3 and then decreases as these are increased from 3 to 4 .

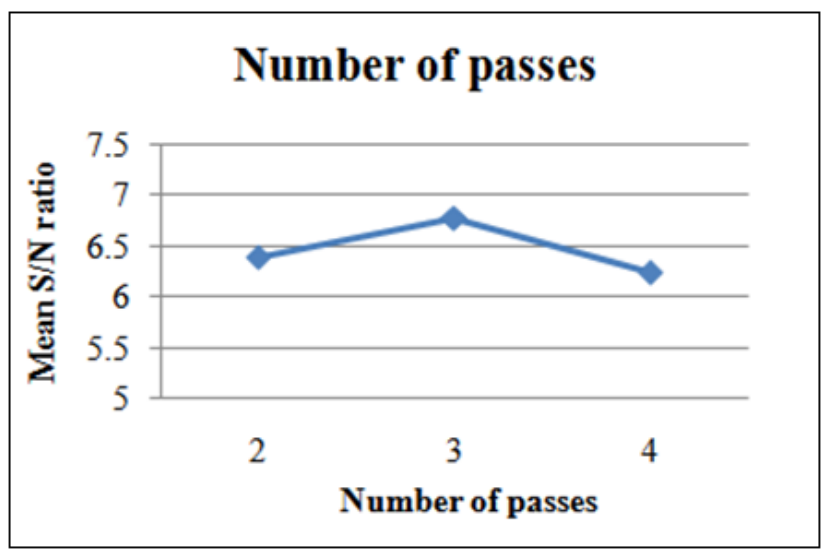

Figure 7. Main effect plots for means of $\mathrm{S} / \mathrm{N}$ ratios of SR for number of passes

\subsection{Optimum Set of Parameters for Surface Roughness}

The higher the signal to noise ratio, the more favorable is the effect of input variable on the output [11]. From Table 7 the optimum values of levels for best surface roughness (minimum) are concluded and shown in Table 4.5. The optimum values of input parameters are grinding wheel speed of $2640 \mathrm{rpm}$, work-piece speed $710 \mathrm{rpm}$, grain size $46 \mathrm{mesh} / \mathrm{inch}$, depth of cut $15 \mu \mathrm{m}$, concentration of cutting fluid $5 \%$ and number of passes 3 .

Table 7. Optimum set of parameters for minimum surface roughness

\begin{tabular}{|c|c|c|c|}
\hline Table 7. Optimum set of parameters for minimum surface roughness \\
\hline Parameter & Units & $\begin{array}{c}\text { Optimum } \\
\text { level }\end{array}$ & $\begin{array}{c}\text { Optimum } \\
\text { value }\end{array}$ \\
\hline Wheel speed & $\mathrm{rpm}$ & A2 & 2640 \\
\hline Work-piece speed & $\mathrm{rpm}$ & $\mathrm{B} 3$ & 710 \\
\hline Grain size & Mesh/inch & C2 & 46 \\
\hline Depth of cut & $\mu \mathrm{m}$ & $\mathrm{D} 1$ & 15 \\
\hline $\begin{array}{c}\text { Concentration of } \\
\text { Cutting fluid }\end{array}$ & $\%$ & E3 & 5 \\
\hline No. of passes & - & F2 & 3 \\
\hline
\end{tabular}

\section{Conclusions}

In this experimental work, the results of six independent variables viz. grinding wheel speed, work piece speed, abrasive grain size, depth of cut, concentration of cutting fluid and number of passes have been studied for surface roughness using ANOVA method. $\mathrm{T}$ he important conclusions are as follows:

1. It has been found that depth of cut and work piece speeds are significant parameters.

2. The variables like grinding wheel speed, grain size, concentration of cutting fluid and number of passes are not significant.

3. Among significant parameters the depth of cut is found to be most significant for surface roughness.

4. The grinding wheel speed is found to be least significant parameter because it shows negligible change of response with change in levels. 
5. Large decrease was observed in surface roughness when depth of cut was increased was increased from $15 \mu \mathrm{m}$ to $20 \mu \mathrm{m}$.

6. It is found that to achieve minimum surface roughness of AISI 4140 steel, the parameters are grinding wheel speed of $2640 \mathrm{rpm}$, work-piece speed of $710 \mathrm{rpm}$, grain size 46 mesh/inch, depth of cut 15 $\mu \mathrm{m}$, concentration of cutting fluid $5 \%$ and number of passes 3 .

\section{References}

[1] Shih, A.J., Grant, M.B., Yonushonis T.M., Morris, T.O., McSpadden, S.B., "Vitreous Bond CBN Wheel for High Speed Grinding of Zirconia and M2 Tool Steel”, Transactions of NAMRI/SME, 26, 195-200, 1998.

[2] Nathan, R.D., Vijayaraghavan, L., Krishnamurthi, R., "In-process Monitoring of Grinding Burn in Cylindrical Grinding of Steel”, Journal of Material Processing Technology, 91, 37-42, 1999.

[3] Shaji, S., Radhakrishnan, V., "Analysis of Process Parameters in Surface Grinding with Graphite as Lubricant based on Taguchi Method”, Journal of Materials Processing Technology, 141, 51-59. 2003.

[4] Sahin, Y., "Optimal Testing Parameters on the Wear Behaviour of Various Steels”, Materials and Design, 27, 455-60. 2005.
[5] Kumar, K., Chattopadhyaya, S., Singh, H., "Optimal Material Removal and Effect of Process Parameters of Cylindrical Grinding Machine by Taguchi Method”, International Journal of Advanced Engineering Research and Studies, 2 (1), 39-43, 2012.

[6] Agarwal, S., Rao, P.V., "Modeling and Prediction of Surface Roughness in Ceramic Grinding”, International Journal of Machine Tools and Manufacture, 50, 1065-76, 2010.

[7] Pal, D., Bangar, A., Sharma, R., Yadav, A., "Optimization of Grinding Parameters for Minimum Surface Roughness by Taguchi Parametric optimization technique", International Journal of Mechanical and Industrial Engineering, 1 (3), pp. 74-78. 2012.

[8] George, L.P., Job, K.V., Chandran, I.M., "Study on Surface Roughness and its Prediction in Cylindrical Grinding Process based on Taguchi method of Optimization”, International Journal of Scientific and Research publications, 3 (5), 2013.

[9] Ptashnikov, V.S., “ Inceasing Work piece Peripheral Speed as a means for Improving Ergonomics of cylindrical up Grinding with Cubic Boron Nitride Tools", Journal of Super Hard Metals, 31, 392-406, 2009.

[10] Alagumurthi, N., Palaniradja, K., and Soundararajan, V., "Heat Generation and Heat Transfer in Cylindrical Grinding Process - a Numerical Study", International Journal of Advanced Manufacturing Technology, 34, 474-82, 2006.

[11] Jagtap, K.R., Ubale, S.B., Kadam, M.S., "Optimization of Cylindrical Grinding Process Parameters for AISI 5120 Steel using Taguchi Method”, International Journal of Design and Manufacturing Technology, 2 (1), 47-56, 2011. 